Elsevier

GEN 02458

\title{
Localization, analysis and evolution of transposed human immunoglobulin $\mathrm{V}_{\kappa}$ genes
}

(Human-rodent cell hybrids; cosmids; restriction maps; ligation artifacts; orphon; recombinant DNA)

\author{
Erika Lötscher a, Franz-Josef Zimmer ", Thomas Klopstock a, Karl-Heinz Grzeschik ${ }^{\mathbf{b}}$, Rita Jaenichen ${ }^{\text {a }}$ \\ Bernhard Straubinger ${ }^{\text {a }}$ and Hans G. Zachau ${ }^{\text {" }}$
}

${ }^{a}$ Institut für Physiologische Chemie, Physikalische Biochemie und Zellbiologie der Universität München, 8000 München 2 (F.R.G.) and ${ }^{b}$ Institut für Humangenetik der Universität Münster, 4400 Münster (F.R.G.)

Received 26 February 1988

Accepted 20 March 1988

Received by publisher 8 April 1988

\section{SUMMARY}

The localization of $\mathrm{V}_{\kappa}$ gene regions to chromosome 2, on which the $\kappa$ locus is located, and to other chromosomes is described. The $V_{\kappa}$ genes that have been transposed to other chromosomes are called orphons. The finding of two new $\mathrm{V}_{\kappa}$ genes on chromosome 22 is reported. $A \mathrm{~V}_{\kappa}$ II gene of this region and two $\mathrm{V}_{\kappa}$ I genes of the $\mathrm{Chr} \mathrm{l}$ and the cos 118 regions were sequenced. The two $\mathrm{V}_{\kappa} \mathrm{I}$ orphon sequences and two others that had been determined previously were $97.5 \%$ identical, indicating that they may have evolved from a common ancestor by amplification. A model of the evolution of the human $\mathrm{V}_{\kappa}$ orphons is discussed.

\section{INTRODUCTION}

The light chains of the $\kappa$ type of the human immunoglobulins are encoded by numerous $\mathrm{V}_{\kappa}$ gene segments and by one $\mathrm{J}_{\kappa}-\mathrm{C}_{\kappa}$ gene segment. Functional $\kappa$ genes are formed by recombination of one $\mathrm{V}_{\kappa}$ gene segment with $\mathrm{J}_{\kappa} \mathrm{C}_{\kappa}$ (for reviews, see

Correspondence to: Dr. H.G. Zachau, Institut für Physiologische Chemie, Goethestrasse 33, 8000 München 2 (F.R.G.) Tel. (089) 5996429.

Present addresses: (E.L.) Howard Hughes Medical Institute, Department of Medicine, University of California, San Francisco, CA 94143 (U.S.A.) Tel. (415) 476-1860; (K.-H.G.) Institut für Humangenetik, Bahnhofstrasse 7a, 3550 Marburg (F.R.G.) Tel. (06421) 284080; (B.S.) Department of Plant Pathology, Cornell University, Ithaca, NY 14853 (U.S.A.) Tel. (607) 255-3200.
Tonegawa, 1983; Honjo and Habu, 1985). A $\mathrm{V}_{\kappa}$ gene of subgroup $I$ and the $\mathrm{C}_{\kappa}$ gene segment has been localized to chromosome 2 (Malcolm et al., 1982; McBride et al., 1982). We have established a physical map of the human $\kappa$ locus comprising about 80 $\mathrm{V}_{\kappa}$ genes, in addition to the $\mathrm{J}_{\kappa} \mathrm{C}_{\kappa}$ gene segment (Lorenz et al., 1987). In the course of our cosmid

\footnotetext{
Abbreviations: aa, amino acid(s); bp, base pair(s); Chr 1, Chr22, $\mathrm{V}_{\kappa}$ gene-containing regions of chromosomes 1 and 22; FR, CDR, framework and complementary determining regions; kb, kilobase(s) or $1000 \mathrm{bp} ; \mathrm{L}, \mathrm{L}^{\prime}$, parts of a leader gene segment; m219-1, the first subclone of the cosmid clone $\cos 219$; orphon, $\mathrm{V}_{\kappa}$ gene outside the $\kappa$ locus on chromosome 2p12; SSC, $0.15 \mathrm{M} \mathrm{NaCl}$, $0.015 \mathrm{M} \mathrm{Na}_{3} \cdot$ citrate, $\mathrm{pH} 7.6 ; \mathrm{V}, \mathrm{J}, \mathrm{C}$, variable, joining and constant gene segments; $V_{\kappa}$ I to $V_{\kappa} I V$, variable gene segments of immunoglobulin light chains of the $\kappa$ type belonging to subgroups I to IV; for reasons of simplicity $V_{\kappa}$ gene segments are generally called $V_{\kappa}$ genes.
} 
cloning experiments we encountered a number of $V_{\kappa}$ genes which lie outside the $\kappa$ locus and which we call orphons, in analogy to the histone and ribosomal RNA genes outside of the respective gene clusters (Childs et al, 1981). Some orphon $V_{\kappa}$ genes have been localized on chromosomes 1 and 22 (Lötscher et al., 1986) and on other chromosomes (Straubinger et al., 1988a). A clustering of putative autonomously replicating sequences has been detected in the $5^{\prime}$ flanks of some $V_{\kappa} I$ orphons indicating that they may have been formed in evolution by over-replication and transposition events (Lötscher et al., 1988).

The finding that $V_{\kappa}$ genes are located not only within the $\kappa$ locus but also outside it made it necessary to determine the chromosomal localization of all known human $\mathrm{V}_{\kappa}$ gene regions. The pertinent experiments are described in the present paper together with structural data on the orphon $V_{\kappa}$ genes. The chromosomal location studies also turned out to be a reliable way to detect ligation artifacts in cosmids which had arisen, as rare events, in the preparation of a cosmid library by ligation of $V_{\kappa}$ gene-containing fragments with DNA fragments derived from other chromosomes. The structural similarities between the transposed $V_{\kappa}$ genes of chromosomes 1 and 22 and of the so-called $\mathrm{Z}$ family (Straubinger et al., 1988) led to speculations on their evolutionary origin.

\section{MATERIALS AND METHODS}

The materials and methods used in the present study were the same as in Straubinger et al. (1988a). In addition, some of the hybridization experiments were carried out in phosphate buffer as described by Church and Gilbert (1984). The mouse-human and hamster-human cell hybrids which were used for the chromosomal location analyses were the same as in Lotscher et al. (1986). The cosmid clones cos 206 and 218 are derived from the cosmid library III (Pohlenz et al., 1987).

\section{RESULTS AND DISCUSSION}

\section{(a) Chromosomal localization of $V_{\kappa}$ gene regions}

In the course of the elucidation of the human $\kappa$ locus, we analyzed numerous $V_{\kappa}$ gene-containing cosmids isolated from genomic DNA libraries. The analyses revealed that some of the $V_{\kappa}$ gene regions occur outside the $\kappa$ locus. To continue the structural work on the human $\kappa$ locus successfully, it was necessary to check systematically the chromosomal localization of $\mathrm{V}_{\kappa}$ regions. The method for the chromosomal localization experiments was the same as used previously (Lotscher et al., 1986). Briefly, specific subclones prepared from the various regions were hybridized to a panel of digested DNAs from human-rodent cell hybrids containing different sets of human chromosomes. The segregation analysis of the fragments and human chromosomes in the panel allows one to assign the regions detected by the probes to specific chromosomes. The essential part of the results is shown in Fig. 1. A full account of the localization experiments is given in Lötscher (1988).

As expected, all of the regions which contained several $\mathrm{V}_{\kappa}$ genes mapped to chromosome 2 . This is shown in Fig. 1 for the A regions (Straubinger et al., 1987 ) and the $O$ and $W$ regions (Pohlenz et al., 1987). The assignment of the $\mathrm{L}$ regions to chromosome 2 has been described previously (Lotscher et al., 1986).

\section{(b) Identification of cosmid ligation artifacts by chromosomal localization experiments}

Even if all steps in the preparation of a cosmid library are carefully controlled, a small amount of ligation artifacts is encountered, which we estimate to be about 3\% (Pohlenz et al., 1987). Chromosomal localization experiments allowed us now to identify two such artifacts.

The first example is the cosmid clone cos 219 (Fig. 2). The subclone m219-1 was clearly localized to chromosome 5 (Fig. 1) but the region upstream from the $V_{\kappa}$ II gene hybridized strongly to the subclone m654-1 of the Wb region (Pohlenz et al., 1987) which is part of chromosome 2 (see above). The sequence of the $\mathrm{V}_{\kappa}$ II gene is identical to that of $\mathrm{W}_{1}$ except for a $T$ instead of a $C$ in the $L-L^{\prime}$ intron ( $T$. Klopstock, unpublished). The left part of $\cos 219$ is therefore probably derived from an allele of the $\mathrm{Wb}$ region and the right part from chromosome 5. No vector sequences were found by hybridization experiments at the point of ligation (indicated in Fig. 2).

Another example of a ligation artifact is the $V_{\kappa} I$ gene-containing clone $\cos 118$ which was thought to 


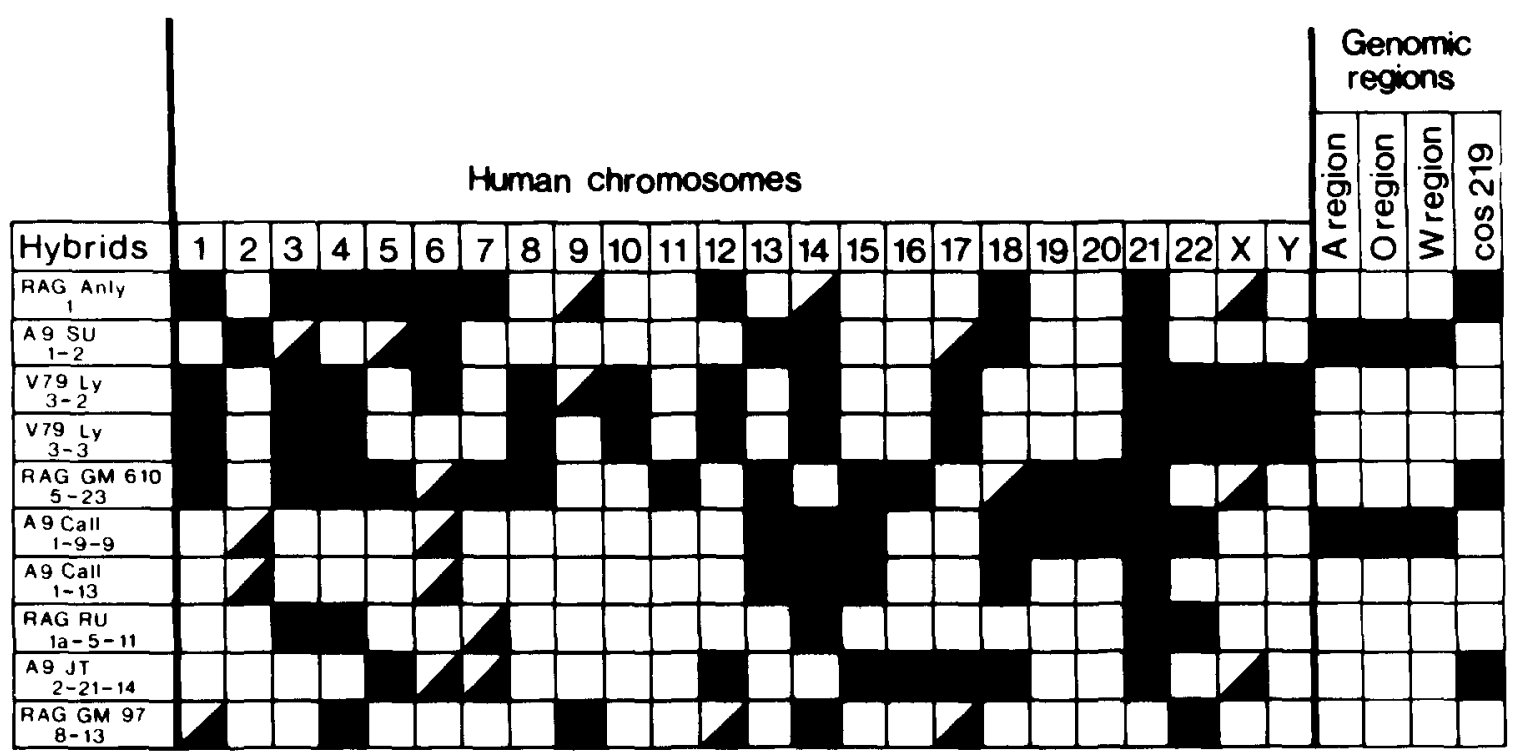

Fig. 1. Chromosomal location of $\mathrm{V}_{\kappa}$ gene-containing regions. The chromosomal locations of the $\mathrm{A}, \mathrm{O}$ and $\mathrm{W}$ regions and of cos 219 (see section a) were carried out using the self-ligated inserts of the clones m163-1 (Straubinger et al., 1987), m143-1 and $\mathrm{m} 167-1$ (Pohlenz et al., 1987) and m219-1 (Fig. 2), respectively. The hybrid cell lines are the same as those used in Lötscher et al. (1986). Filled spaces indicate the presence of the chromosome in the respective cell line; half-filled spaces mean that part of the chromosome is present, and empty spaces indicate that the chromosome was not detected by biochemical and cytogenetic analyses.

be located on chromosome 15 on the basis of hybridization experiments with a subclone from the left side of the cosmid clone (Lötscher et al., 1986). It was then shown, by hybridization with parts of the vector pHC79 and by sequencing, that a fragment near the break-off of homology to the Chrl map (Fig. 1 in Lotscher et al., 1986) is derived from the vector. It was not possible to prepare a single copy subclone from the right side of the cosmid clone which would permit the chromosomal localization of the $V_{\kappa}$ I gene region of $\cos 118$. However, according to its map (Lotscher et al., 1988) and the sequence of the gene (see below) it is closely related to both $\mathrm{Chr} 1$ and the $\mathrm{Z}$ family (Straubinger et al., 1988). Apparently an orphon $\mathrm{V}_{\kappa}$ I gene region had been artifactually ligated to a vector fragment and to a fragment derived from chromosome 15 . The experiments which led to the clarification of this situation have been documented (Lotscher, 1988).

The lesson learned from these two artifacts is that chromosomal localization analyses should be done for all cosmid clones which are isolated only once from a library and which contain long regions free of genes.

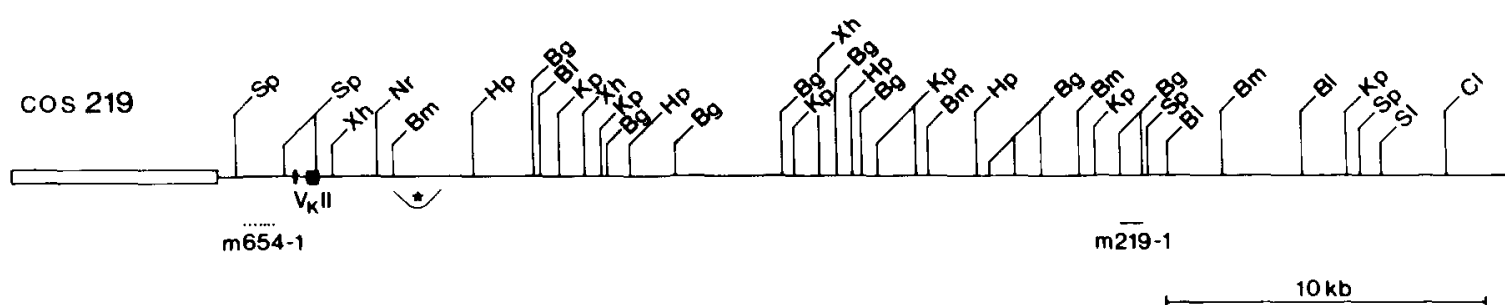

Fig. 2. Restriction map of the $\cos 219$ region. The restriction map shows the product of the ligation of two different genomic fragments. The site of ligation is within the bracket indicated by an asterisk. The subclone m219-1 marked by a line was localized to chromosome 5 (Fig. 1). The subclone m654-1 derived from the Wb regions on chromosome 2 (Pohlenz et al., 1987) hybridizes to the fragment of cos 219 indicated by a short dotted line. The $V_{\kappa}$ II gene sequence and the restriction map around the gene are identical to those of the gene W1 (Pohlenz et al., 1987). The abbreviations of the restriction nucleases are the same as in Fig. 3. 


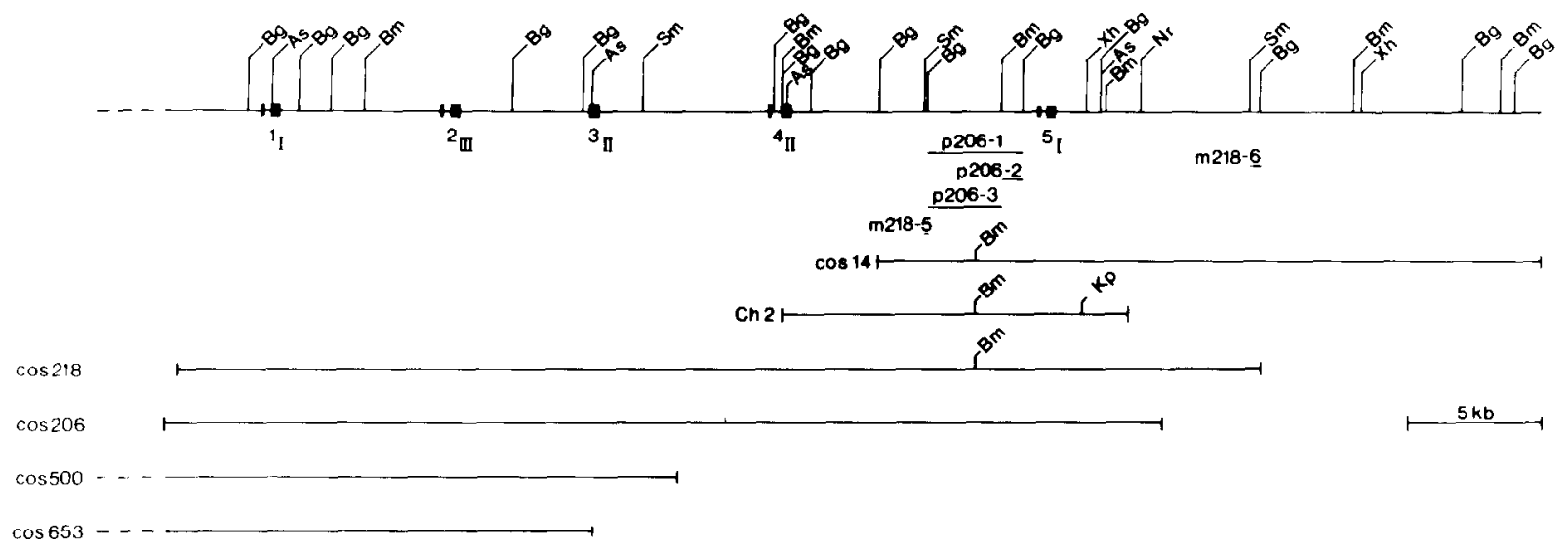

Fig. 3. Restriction map of part of the genomic region $\mathrm{Chr} 22$. The restriction map contains an extension to the 3' direction compared to the one by Lötscher et al. (1986). The $V_{\kappa}$ genes and leaders are indicated by filled boxes; the suffixes at the gene numbers specify the subgroups. Horizontal bars show the lengths of the cosmids. The presence of additional restriction sites which occur only in the respective cosmids are indicated. The designations of the clones cos 500 and $\cos 653$ are the same as in Bauer et al. (1986). The subclones are shown as short horizontal lines. The fragments 206-1 to 3 were subcloned into the vector ptk (Holst et al., 1988). Restriction nucleases are abbreviated: As, Asp 718; Bg, BglII; BI, BglI; Bm, BamHI; Cl, ClaI; Dr, DraI; Ec, EcoRI; Hp, HpaI; HIII, HindIII; Kp, KpnI; Nr, NruI; Ps, PstI; Pv, PvuI; PII, PvuII; Sl, SalI; Sm, SmaI; Sp, SphI; Xh, XhoI.
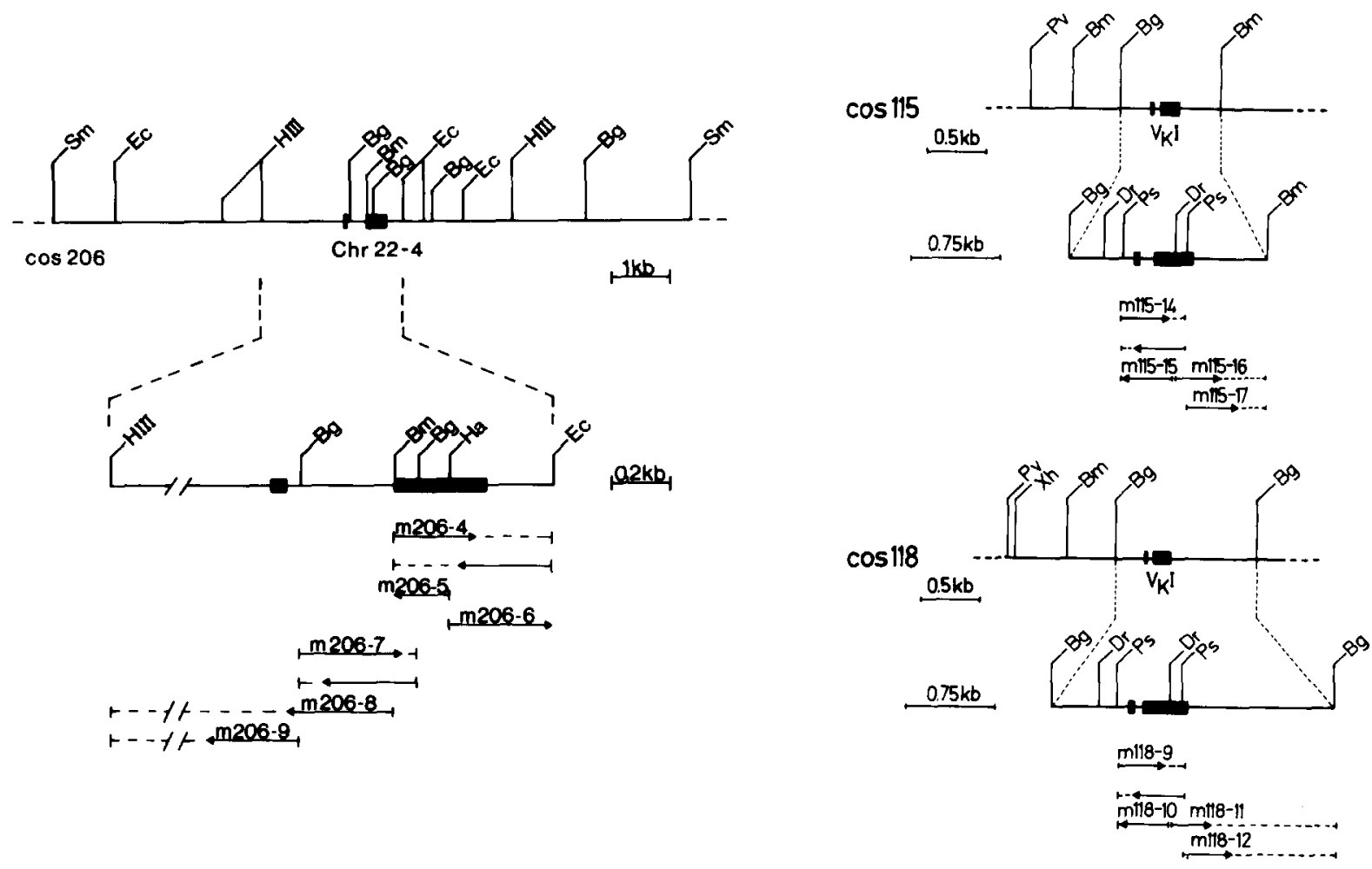

Fig. 4. Restriction maps and sequencing strategies of $\mathrm{V}_{\kappa}$ genes of the Chr1 (cos115) and Chr22 (cos206) genomic regions and of cos 118. Gene segments are shown as filled boxes. Extent and direction of sequencing are symbolized by arrows. The horizontal dashed lines indicate the lengths of the fragments cloned into M13 vectors; arrows indicate the extent of sequencing. The abbreviations of the restriction nucleases are the same as in Fig. 3. 


\section{(c) The Chr22 region contains five $V_{\kappa}$ genes}

Most of the $V_{\kappa}$ regions located outside the $\kappa$ locus contain a single $\mathrm{V}_{\kappa}$ gene of the subgroup I (Lötscher et al., 1986; Straubinger et al., 1988a). However, a cluster of three $V_{\kappa}$ genes could be shown to be part of a region which has been transposed to chromosome 22 (Lötscher et al., 1986). The restriction map of the Chr22 region could be extended now in the $3^{\prime}$ direction by the two cosmid clones cos 206 and cos 218 which were isolated from genomic DNA libraries with the help of two $\mathrm{V}_{\kappa}$ II-specific probes (m607V-3; Klobeck et al., 1984, and m106-1, a 448-bp PstI clone comprising part of the $\mathrm{Vc}^{\prime \prime}$ gene; Pech et al., 1985). In addition, the $\lambda$ Charon phage $\mathrm{Ch} 2$ and the cosmid clone cos 14 which had been isolated previously (Jaenichen et al., 1984) overlap with the extended restriction map of the $\mathrm{Chr} 22$ region. The extending phage and cosmid clones were assigned to chromosome 22 on the basis of restriction map homologies and hybridization experiments. The subclone m218-6 (Fig. 3) which was prepared for further chromosomal walking in the $3^{\prime}$ direction contained low repetitive sequences and therefore could not be used.

Ligation artifacts are rather unlikely in the Chr22 region since most of it is derived from several overlapping clones (Fig. 3, and Lötscher et al., 1986). In addition, a subclone prepared from the region upstream from the gene Chr22-2 (m120-12 in Bauer et al., 1986) was found to hybridize to the DNA of chromosome 22-containing hybrid cell lines (not shown). That the subclone hybridized also to the chromosome 2-containing cell lines is explained by its proximity to a $V_{\kappa}$ III gene and the general homology of flanking sequences of $\mathrm{V}_{\kappa}$ genes of certain subgroups.

The new 3' part of the Chr22 region turned out to contain two additional $V_{\kappa}$ genes. The sequence of the $V_{\kappa}$ II gene Chr22-4 is reported below. The sequence of an allele of the $V_{\kappa}$ I gene Chr22-5 had been determined previously in the phage clone $\mathrm{Ch} 2$ (V2 in Jaenichen et al., 1984). It is interesting that the Chr22-5 gene and its $5^{\prime}$ and $3^{\prime}$ flanks are highly homologous to the $V_{\kappa}$ I gene regions of other orphons (Lotscher et al., 1988).

\section{(d) Nucleotide sequences of three transposed $V_{k}$ genes}

To determine the degree of homology between transposed genes and genes located in the $\kappa$ locus, the gene Chr22-4 of the $\mathrm{Chr} 22$ region, as well as the genes of the $\mathrm{Chr} 1$ and cos 118 regions, were sequenced. The sequencing strategies are shown in Fig. 4. The sequence of the gene Chr22-4 (Fig. 5) is very similar to the $\mathrm{V}_{\kappa}$ II genes of the $\kappa$ locus. Only one of the 57 invariant aa (Kabat et al., 1987) is changed: at aa position 7 of FRl the serine is replaced by a threonine. The regulatory sequences and recognition signals correspond to the respective consensus sequences. However, at position 81 of FR3, the stop codon TAG was found. Besides the chromosomal localization of the gene on chromosome 22 the occurrence of the stop codon is the only indication which points to a non-functional $V_{\kappa}$ gene.

The $V_{\kappa} I$ genes of both the Chrl and $\cos 118$ regions contain a mutation in the start codon (Fig. 6). It should be noted, however, that the third codon is a start or methionine codon. The regulatory sequences of the two genes correspond to the respective consensus sequences. Three and four of the 29 invariant amino acids of subgroup I (Kabat et al., 1987) are changed in the genes of the Chr l and cos 118 regions, respectively. The latter gene also contains a TAG stop codon in FR3.

\section{(e) Comparison of the sequences of four transposed $V_{\boldsymbol{x}}$ I genes}

A characteristic feature of all transposed $V_{\kappa}$ regions analyzed so far is the presence of $V_{\kappa} I$ gene regions with very similar restriction maps. To determine how far the homology extends to the sequence level the sequences of the $\mathrm{V}_{\kappa}$ I genes of the Chr 1, the $\cos 118$, and the $\mathrm{ZI}$ regions were compared to the sequence of the V2 gene which corresponds to Chr22-5 (Fig. 6). In addition to the coding sequences, $112 \mathrm{bp}$ of the $5^{\prime}$ flank and $175 \mathrm{bp}$ of the $3^{\prime}$ flank were included in the comparison. The overall identity proved to be $97.5 \%$. This number is in the same range as is found for allelic or duplicated $V_{\kappa}$ genes within the $\kappa$ locus. In contrast, the average homology between randomly chosen $V_{\kappa} I$ genes is about $90 \%$. In addition, four identical mutations in comparison to a potentially functional $V_{\kappa} I$ gene 
L

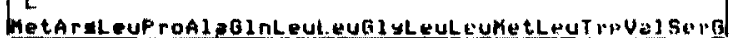

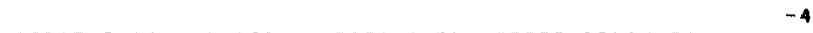

AATGAOBCTCCCTGCTCAGCTCCTGGBGCTBCTAATGCTETBGGTCTCTËGTAAGGATABGATCAAAABTBAGGTGAGAAAATGGGGTGGGAGGGTGAGA -34

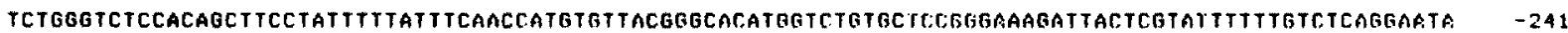

L' $\quad$ FRI

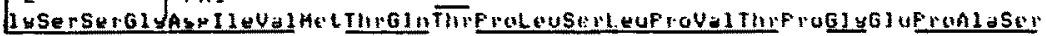

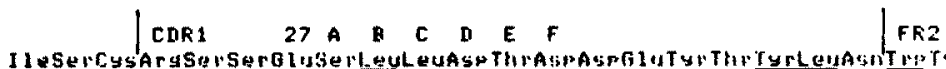

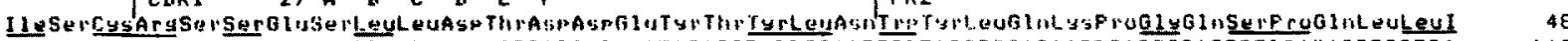

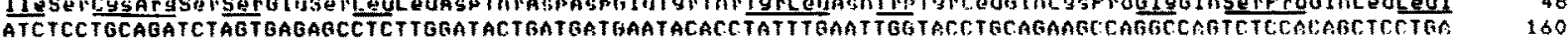

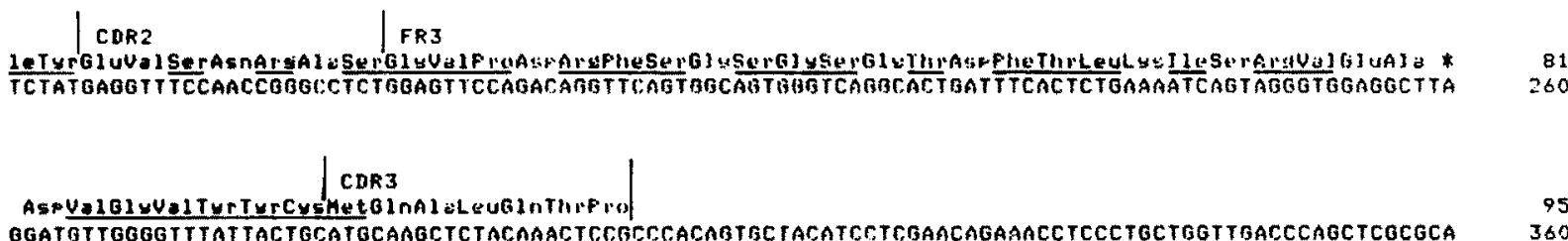

GGATGTTGGGGTTTATTACTGCATGCAAGCTCTACAAACTCCGCCCACABTHCTACATCETCOAACAGAAACCTCCCTGCTGGTTGACCCAGCTCGCGCA 3GO

OTCCATGACABCCT

Fig. 5. Nucleotide sequence and deduced amino acid sequence of the $V_{\kappa}$ II gene Chr22-4. The sequence was determined following the strategy shown in Fig. 4. Invariant amino acids of subgroup II (Kabat et al., 1987) are underlined. A horizontal line above an aa symbol indicates that an invariant amino acid has been replaced by another amino acid. A conserved pentekaidecanucleotide, the decanucleotide promoter (Falkner and Zachau, 1984), a TATA box and the hepta- and nonanucleotide boxes are underlined. The asterisk marks a stop codon. The numbering and the division into $L, L^{\prime}$, FRI etc. is as in Kabat et al. (1987).

have been found in the $V_{\kappa} I$ orphons: the start codon is changed in each case to ACG or ACA and 3 invariant aa have been replaced by the same substitute amino acid (Fig. 6). The high sequence homology as well as the identical mutations in the transposed sequences led to the hypothesis that the human $\mathrm{V}_{\kappa}$ orphons stem from a common ancestor. (f) Concluding remarks on the evolution of the orphon $V_{\kappa}$ genes

A hypothetical scheme of the evolution of the orphon $V_{\kappa}$ genes is outlined in Fig. 7. We assume that the five genes of $\mathrm{Chr} 22$ have been transposed in a single event to chromosome 22 since it is unlikely 
L

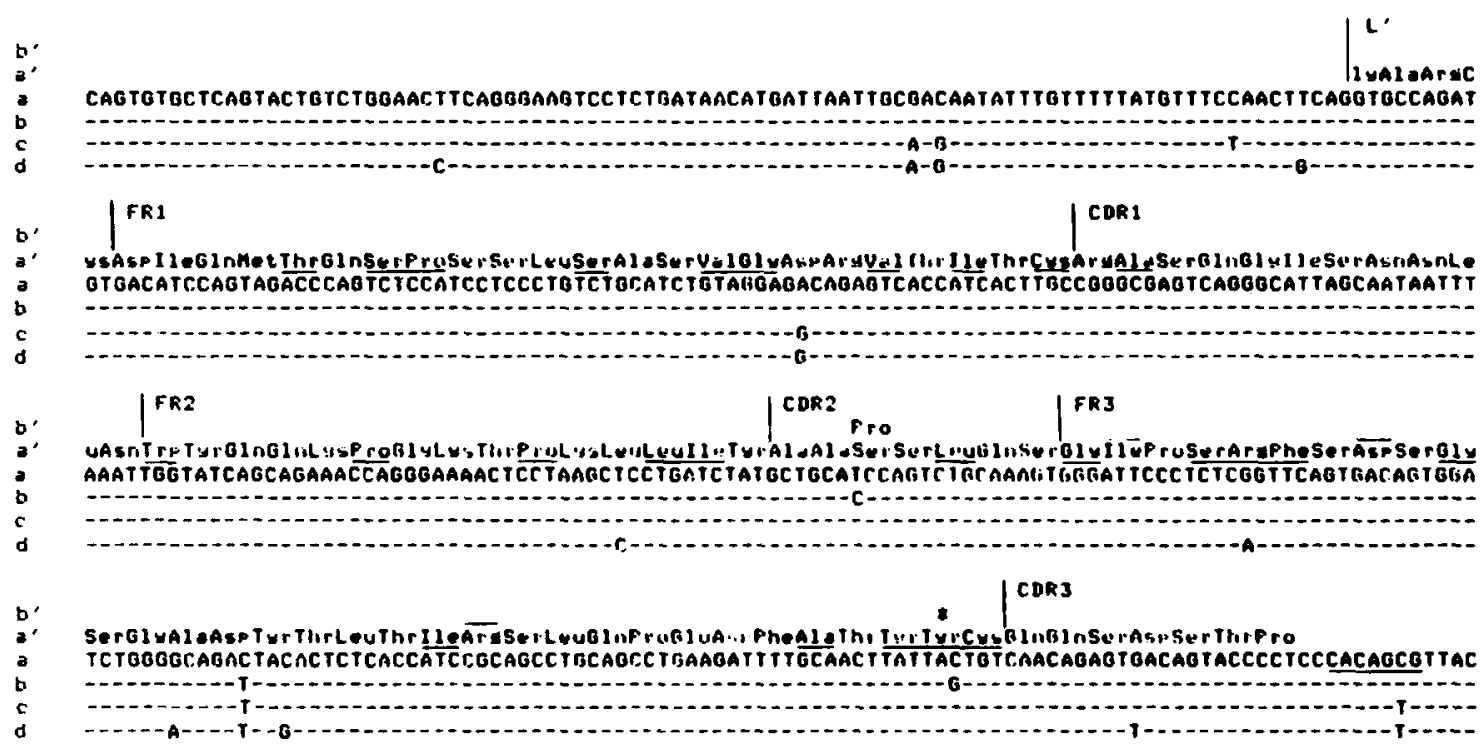

Fig. 6. Sequence comparison of four orphon $V_{\kappa} I$ genes. The sequences of the orphon $V_{\kappa} I$ genes of the genomic regions of Chr 1 (a) and $\cos 118$ (b) were determined following the strategies shown in Fig. 4. The respective formal translation products $a^{\prime}$ and $b^{\prime}$ are also shown. The gene of the ZI region (c) and the allele V2 of the Chr22-5 gene (d) are taken from Straubinger et al. (1988a) and Jaenichen et al. (1984), respectively. Sequences were aligned for maximum homology with the help of sequence editor DNMAHO (Pech et al., 1984). The numbering, partitioning by vertical lines, the asterisk and lines above and below the symbols are as in Fig. 5 .

that several transposition events have occurred independently to the same region of one chromosome. Whether the Chr22 transposition event has been duplicative or not is not clear. However, we have not so far found an apparent ancestral region within the $\kappa$ locus, either by hybridization experiments or comparison of restriction maps.

The conserved $V_{\kappa} I$ gene regions of the other orphons have been transposed to the other chromosomes from either the $\mathrm{Chr} 22$ region in a duplicative event or directly from the $\kappa$ locus in a duplicative or non-duplicative event. It is possible that the $\mathrm{Chr} 1$ and $\mathrm{Z}$ families have a common intermediate. In evolution there have probably been several amplification events involving the conserved $\mathrm{V}_{\kappa} \mathrm{I}$ gene regions, since their co-amplified surroundings are different in ZI-ZIV (Straubinger et al., 1988), and in Chrl also there are at least two types of constituent cosmids (Pohlenz, 1986). A clustering of putative replicating and/or recombinogenic elements upstream from the $V_{\kappa} I$ orphons, described in an accompanying paper (Lotscher et al., 1988), may have 


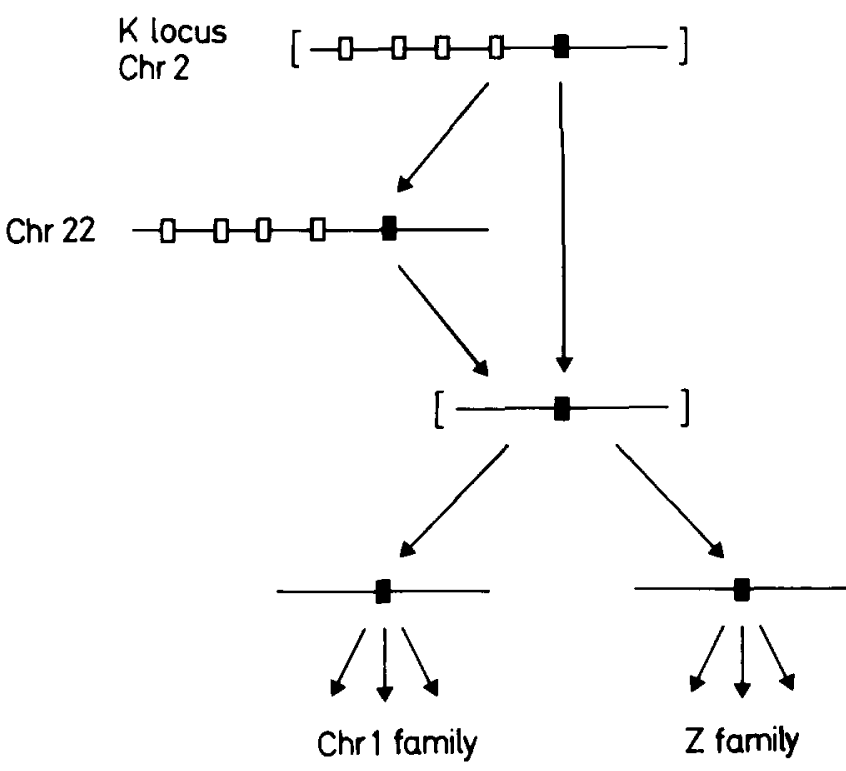

Fig. 7. Hypothetical model of the evolution of the human orphon $V_{K}$ genes (section $f$ of the text). Open boxes indicate the Chr22-1 to 4 genes, the filled boxes the conserved $V_{\kappa} I$ genes of $\mathrm{Ch}+22$, $\mathrm{Chr}$, and the $Z$ regions. The regions in square brackets indicate the hypothetical ancestor on chromosome 2 and a possible intermediate. The gene-containing parts of the Chr22, Chrl and Z regions are compiled in Fig. 1 of Lotscher et al. (1988). The maps of Chr 22 and Chr 1 are described in Lötscher et al. (1986), those of the $Z$ regions in Straubinger et al. (1988b).

been the cause of their over-replication and eventual transposition during evolution.

\section{ACKNOWLEDGEMENTS}

The work was supported by Bundesministerium für Forschung und Technologie and Fonds der Chemischen Industrie. F.-J.Z. is the holder of an A. Butenandt fellowship. K.-H.G. acknowledges the technical assistance of G. Schwartenbeck.

\section{REFERENCES}

Bauer, H.G., Pech, M. and Zachau, H.G.: Characterization of a group of transposed human $V_{\kappa}$ genes. Biol. Chem. 367 (1986) 751-755.

Church, G.M. and Gilbert, W.: Genomic sequencing. Proc. Natl. Acad. Sci. USA 81 (1984) 1991-1995.
Falkner, F.G. and Zachau, H.G.: Correct transcription of an immunoglobulin $\kappa$ gene requires an upstream fragment containing conserved sequence elements. Nature 310 (1984) 71-74.

Holst, A., Müller, F., Zastrow, G., Zentgraf, H., Schwender, S., Dinkl, E. and Grummt, F.: Murine genomic DNA sequences replicating autonomously in mouse L cells. Cell 52 (1988) 355-365.

Honjo, T. and Habu, S.: Origin of immune diversity: genetic variation and selection. Annu. Rev. Biochem. 54 (1985) 803-830.

Jaenichen, H.R., Pech, M., Lindenmaier, W., Wildgruber, N. and Zachau, H.G.: Composite human $\mathrm{V}_{\kappa}$ genes and a model of their evolution. Nucleic Acids Res. 12 (1984) 5249-5263.

Kabat, E.A., Wu, T.T., Reid-Miller, M., Perry, H. and Gottesman, K.S.: Sequences of proteins of immunological interest. National Institutes of Health, Bethesda, MD, 1987.

Klobeck, H.-G., Solomon, A. and Zachau, H.G.: Contribution of human $\mathrm{V}_{\kappa}$ II germ-line genes to light-chain diversity. Nature 309 (1984) 73-76.

Lorenz, W., Straubinger, B. and Zachau, H.G.: Physical map of the human immunoglobulin $\kappa$ locus and its implications for the mechanisms of $\mathrm{V}_{\kappa}-\mathrm{J}_{\kappa}$ rearrangement. Nucleic Acids Res. 15 (1987) 9667-9676.

Lötscher, E., Grzeschik, K.-H., Bauer, H.G., Pohlenz, H.-D., Straubinger, B. and Zachau, H.G.: Dispersed human immunoglobulin $\kappa$ light-chain genes. Nature 320 (1986) 456-458.

Lötscher, E., Siwka, W., Zimmer, F.J., Grummt, F. and Zachau, H.G.: Transposed human immunoglobulin $V_{\kappa}$ genes carry clusters of putative autonomously replicating sequence elements. Gene 69 (1988) 225-236.

Lötscher, E.: Menschliche Immunglobulingene vom $\kappa$-Typ: Variabele Gensegmente innerhalb und ausserhalb des $\kappa$-Locus. Ph. D. Thesis, Fakultät für Biologie der Universität München, München, 1988.

Malcolm, S., Barton, P., Murphy, C., Ferguson-Smith, M.A., Bentley, D.L. and Rabbitts, T.H.: Localization of human immunoglobulin $\kappa$ light chain variable region genes to the short arm of chromosome 2 by in situ hybridization. Proc. Natl. Acad. Sci. USA 79 (1982) 4957-4961.

McBride, O.W., Hieter, P.A., Hollis, G.F., Swan, D., Otey, M.C. and Leder, P.: Chromosomal location of human kappa and lambda immunoglobulin light chain constant region genes. $\mathbf{J}$. Exp. Med. 155 (1982) 1480-1490.

Pech, M., Jaenichen, H.R., Pohlenz, H.-D., Neumaier, P.S., Klobeck, H.-G. and Zachau, H.G.: Organization and evolution of a gene cluster for human immunoglobulin variable regions of the kappa type. J. Mol. Biol. 176 (1984) 189-204.

Pech, M., Smola, H., Pohlenz, H.-D., Straubinger, B., Gerl, R. and Zachau, H.G.: A large section of the gene locus encoding human immunoglobulin variable regions of the kappa type is duplicated. J. Mol. Biol. 183 (1985) 291-299.

Pohlenz, H.-D.: Organisation menschlicher Immunglobulingene. Isolierung und Analyse von Regionen des menschlichen $\mathrm{V}_{\kappa}$-Locus durch Cosmidklonierung. $\mathrm{Ph}$. D. Thesis, Fakultät für Chemie und Pharmazie der Universität München, München, 1986. 
Pohlenz, H.-D., Straubinger, B., Thiebe, R., Pech, M., Zimmer, F.-J. and Zachau, H.G.: The human $\mathrm{V}_{\kappa}$ locus: characterization of extended immunoglobulin gene regions by cosmid cloning. J. Mol. Biol. 193 (1987) 241-253.

Straubinger, B., Huber, E., Lorenz, W., Osterholzer, E., Pargent, W., Pech, M., Pohlenz, H.-D., Zimmer, F.-J. and Zachau, H.G.: The human $\mathrm{V}_{\kappa}$ locus: characterization of a duplicated region encoding 28 different immunoglobulin genes. J. Mol. Biol. 199 (1988a) 23-34.
Straubinger, B., Thiebe, R., Pech, M. and Zachau, H.G.: The Z family, a group of transposed human immunoglobulin $V_{\kappa}$ genes. Gene 69 (1988b) 209-214.

Tonegawa, S.: Somatic generation of antibody diversity. Nature 302 (1983) 575-581.

Communicated by $Z$. Hradečná. 